\title{
Upaya Peningkatan Pengetahuan dan Sikap Ibu Hamil dalam Program Perencanaan Persalinan dan Pencegahan Komplikasi (P4K) melalui Pemberdayaan Kader
}

\section{Efforts to Increase Pregnant Woman's Knowledge and Attitudes in Childbirth Planning Programs and The Prevention of Complications (P4K) Through Empowering Cadres}

\author{
Lisma Ningsih ${ }^{1}$, Daisy Novira ${ }^{2}$ \\ ${ }^{1}$ Jurusan Promosi Kesehatan, Politeknik Kesehatan Kementerian Kesehatan Bengkulu, Indonesia \\ ${ }^{2}$ Jurusan Keperawatan, Politeknik Kesehatan Kementerian Kesehatan Bengkulu, Indonesia
}

\section{ARTICLE INFO}

\section{Article history}

Received date

07 Oct 2020

Revised date

27 Oct 2020

Accepted date

25 Nov 2020

Keywords:

Attitude;

Cadres empowerment;

Knowlegde;

Pregnant women;

P4K.

Kata kunci:

Sikap;

Pemberdayaan kader;

Pengetahuan;

Ibu hamil;

P4K.

\section{ABSTRACT/ ABSTRAK}

\begin{abstract}
As a breakthrough in accelerating the reduction in maternal mortality rates, the government since 2007 has launched a Maternity Planning and Prevention Complications Program (P4K). One effort to increase knowledge is health promotion with a community empowerment strategy. This study aimed to determine the effect of empowering cadres on the knowledge and attitudes of pregnant women about P4K. The study design used a quasi-experimental design by pre and post-test with control group design. The study population was all pregnant women, the sample was pregnant women who were selected purposively consisted of 60 people, 30 people in the intervention group, and 30 control groups. To analyze the data, the researcher used a paired t-test and independent t-test. The results showed that in the intervention group there was an increase of knowledge score $(70,67)$ for before and $(92,50)$ for after cadres empowerment, while in the control group there was no difference in the average knowledge score $(74,67)$ before and $(71,00)$ after an intervention ( $p$-value 0,351$)$. Moreover, In the intervention group, there was an increase in the attitude score of pregnant women before (78.67) and after (86.12) cadres empowerment, but in the control group there was no difference in the average attitude score before $(77,46)$ and after $(77,67)$ intervention ( $p$-value=0,524). Empowering cadres can increase the knowledge and attitudes of pregnant women about P4K. It is hoped that the Health Office will further improve the implementation of $\mathrm{P} 4 \mathrm{~K}$ on an ongoing basis through the active role of the community, especially cadres.
\end{abstract}

Upaya terobosan dalam mempercepat penurunan Angka Kematian Ibu (AKI), pemerintah telah mencanangkan Program Perencanaan Persalinan dan Pencegahan Komplikasi (P4K) sejak tahun 2007. Salah satu upaya meningkatkan pengetahuan adalah promosi kesehatan dengan strategi pemberdayaan masyarakat (empowerment). Penelitian ini bertujuan untuk mengetahui pengaruh pemberdayaan kader terhadap pengetahuan dan sikap ibu hamil tentang P4K. Desain penelitian quasi eksperimen dengan rancangan pre and post test with control group design. Populasi penelitian seluruh ibu hamil, sampel penelitian ibu hamil yang dipilih secara purposif sebanyak 60 orang, terdiri dari 30 orang kelompok intervensi dan 30 orang kelompok kontrol. Instrumen yang digunakan adalah kuesioner terstruktur yang terdiri dari 20 butir pertanyaan pengetahuan dan 20 butir pertanyaan sikap. Analisis data menggunakan paired t-test dan independent t-test. Hasil menunjukkan kelompok intervensi terdapat peningkatan rerata skor pengetahuan sebelum $(70,67)$ dan sesudah $(92,50)$ pemberdayaan kader, sedangkan pada kelompok kontrol tidak ada perbedaan rerata skor pengetahuan sebelum $(74,67)$ dan sesudah $(71,00)$ intervensi $(p$-value $=0,351)$. Pada kelompok intervensi, terjadi peningkatan skor sikap ibu hamil sebelum $(78,67)$ dan sesudah $(86,12)$ pemberdayaan kader, namun pada kelompok kontrol tidak ada perbedaaan rerata skor sikap sebelum $(77,46)$ dan sesudah $(77,67)$ intervensi ( $p$-value $=0,524)$. Pemberdayaan kader dapat meningkatkan pengetahuan dan sikap ibu hamil tentang P4K. Diharapkan Dinas Kesehatan lebih meningkatkan pelaksanaan P4K secara berkesinambungan melalui peran aktif masyarakat terutama kader.

Corresponding Author:

Lisma Ningsih

Jurusan Promosi Kesehatan, Politeknik Kesehatan Kementerian Kesehatan Bengkulu, Indonesia Email: lisma091074@gmail.com 


\section{PENDAHULUAN}

Program pembangunan kesehatan di Indonesia masih di prioritaskan pada upaya peningkatan derajat kesehatan ibu dan anak terutama pada kelompok yang paling rentan yaitu ibu hamil dan bersalin serta bayi pada masa perinatal (Badan Penelitian dan Pengembangan Kesehatan Kemenkes RI, 2016). Salah satu sasaran pokok Rencana Pembangunan Jangka Menengah Nasional (RPJMN) 2015-2019 adalah meningkatnya status kesehatan dan gizi ibu dan anak. Indikator utama kesehatan ibu adalah Angka Kematian Ibu (AKI), sedangkan indikator kesehatan anak antara lain adalah Angka Kematian Neonatal (AKN) dan Angka Kematian Bayi (AKB). AKI masih merupakan masalah kesehatan di Indonesia, ini terlihat dari hasil data SDKI 2012 dilaporkan sebesar 359 per 100.000 Kelahiran Hidup (KH). Angka ini masih jauh dari target MDGs 2015 yakni 102 per $100.000 \mathrm{KH}$ dan target dalam RPJMN 2015-2019 sebesar 306 per 100.000 KH (Kemenkes RI, 2015). Selanjutnya masih menurut data SDKI tahun 2012 disebutkan bahwa AKN di Indonesia sebesar 19 per $1.000 \mathrm{KH}$, sedangkan AKB sebesar 32 per $1.000 \mathrm{KH}$ (Pusat Data dan Informasi Kemenkes RI, 2014).

Profil Kesehatan Propinsi Bengkulu melaporkan bahwa jumlah kematian ibu di Propinsi Bengkulu pada tahun 2017 sebanyak 28 orang. Kematian ibu tertinggi di Kabupaten Seluma sebanyak 5 orang diikuti Kota Bengkulu sebanyak 4 orang. Dalam Profil tersebut dilaporkan juga jumlah kematian neonatal sebanyak 273 orang, sedangkan jumlah kematian bayi sebanyak 43 orang (Dinas Kesehatan Provinsi Bengkulu, 2018).

Pada tahun 2018 jumlah kematian ibu meningkat menjadi 39 orang. Terjadi peningkatan AKI dari tahun 2017 sebesar 79 per 100.000 Kelahiran Hidup (KH) menjadi 111 per $100.000 \mathrm{KH}$ pada tahun 2018. Walaupun terjadi peningkatan namun sudah berada dibawah target yaitu sebesar 115 per $100.000 \mathrm{KH}$. Kematian ibu tertinggi di Kota Bengkulu sebanyak 12 orang. Di Kota Bengkulu, kematian ibu terbanyak di wilayah Puskesmas Sukamerindu yakni 2 orang. Jika dilihat dari trend kematian ibu di Kota Bengkulu dari tahun ke tahun mengalami fluktuasi, Tahun 2016 sebanyak 6 orang, tahun 2017 menurun menjadi 4 orang dan tahun 2018 meningkat menjadi 12 orang. Data Profil Kesehatan Propinsi Bengkulu menunjukkan bahwa jumlah sasaran ibu hamil di Propinsi Bengkulu pada tahun 2018 sebanyak 41.005 orang dan ibu hamil risiko tinggi sebanyak 8.201 orang. Jika dilihat dari 10 Kabupaten/Kota di Propinsi Bengkulu, jumlah sasaran ibu hamil tertinggi adalah di Kota Bengkulu sebanyak 7.489 orang dan ibu hamil risiko tinggi sebanyak 1.498 orang (Dinas Kesehatan Provinsi Bengkulu, 2019).

Program Perencanaan Persalinan dan Pencegahan Komplikasi (P4K) merupakan salah satu upaya dalam mempercepat penurunan angka kematian ibu dan bayi baru lahir. Program ini menjadi indikator utama Rencana Strategis (Renstra) Kementerian Kesehatan tahun 20152019 yakni persentase Puskesmas yang melaksanakan orientasi P4K (Badan Penelitian dan Pengembangan Kesehatan Kemenkes RI, 2016). Berdasarkan Survei Indikator Kesehatan Nasional (Sirkesnas) tahun 2016, dilaporkan bahwa persentase puskesmas yang sudah melaksanakan orientasi $\mathrm{P} 4 \mathrm{~K}$ adalah sebesar $88,8 \%$ dan jika dibandingkan dengan target tahun 2016 sebesar $83 \%$ berarti indikator ini sudah tercapai. Orientasi pada kader sebesar $92,1 \%$ dan bidan sebesar $85,37 \%$, ini mengindikasikan bahwa sebagian besar kader sudah tidak asing lagi dengan program P4K. Namun berdasarkan observasi stiker pada rumah responden ditemukan informasi bahwa ibu hamil yang mendapatkan stiker sebesar $25,8 \%$, terisi lengkap $18,2 \%$ dan stiker yang tidak ditemukan atau di tempel di rumah sebesar 49,6\% (Badan Penelitian dan Pengembangan Kesehatan Kemenkes RI, 2016).

Penelitian Amalia NM, dkk (2016) menyebutkan bahwa faktor keterlambatan rujukan yang meliputi keterlambatan dalam pengambilan keputusan dari pihak keluarga masih memegang peranan penting pada kejadian kematian maternal di Kabupaten Batang. Selain itu rendahnya kemampuan untuk mengenali tanda-tanda kegawatdarutan kebidanan,seperti edema pada tangan dan kaki,nyeri kepala, perdarahan yang terjadi saat kehamilan maupun persalinan, infeksi dan persalinan bayi kedua dalam persalinan kembar. Terlambat dalam pengambilan keputusan bisa disebabkan karena kurangnya pengetahuan tentang masalah kesehatan yang terjadi, disamping faktor dominan suami dalam keluarga dan faktor biaya. Demikian juga dengan penelitian Mariani P., dkk (2013) tentang hambatan dalam implementasi P4K di Kabupaten Badung menunjukkan bahwa pengetahuan, sikap dan perilaku ibu hamil dan keluarga tentang P4K masih kurang. Ibu hamil dan keluarga tidak mengetahui tujuan dan komponen yang dipersiapkan dalam menghadapi persalinan karena kurangnya informasi dari petugas kesehatan. 
Promosi kesehatan dapat meningkatkan pengetahuan. Melalui promosi kesehatan, bukan hanya proses penyadaran masyarakat atau pemberian dan peningkatan pengetahuan masyarakat saja, tetapi juga disertai upaya-upaya memfasilitasi perubahan perilaku (Notoadmodjo, 2010). Menurut WHO (1984) dalam Subaris H (2016), salah satu strategi promosi kesehatan adalah pemberdayaan masyarakat (empowerment), agar masyarakat mempunyai kemampuan untuk meningkatkan kesehatannya.

Penelitian ini bermaksud memberdayakan kader puskesmas yang aktif dan peduli terhadap kesehatan ibu dan anak. Adapun tujuan penelitian ini adalah untuk mengetahui pengaruh pemberdayaan kader terhadap pengetahuan dan sikap ibu hamil tentang Program Perencanaan Persalinan dan Pencegahan Komplikasi (P4K).

\section{METODE}

Desain penelitian ini adalah quasi eksperimen dengan rancangan pre-post-test with control group design. Penelitian dibagi dalam tiga tahap, tahap pertama pembentukan dan pelatihan kelompok kader selama tiga hari, tahap kedua kader melakukan pendampingan terhadap ibu hamil dengan cara memberikan promosi kesehatan, bimbingan dan konseling selama satu bulan dan tahap ketiga pengukuran pengaruh pemberdayaan kader terhadap pengetahuan dan sikap ibu hamil tentang P4K. Jumlah Kader dalam penelitian ini sebanyak 10 orang. Masingmasing kader mendampingi 3 orang ibu hamil.

Pemberdayaan kader dalam penelitian ini adalah memampukan kader dalam menjalankan perannya, mulai dari pelatihan kader yang dilakukan selama tiga hari, selanjutnya kegiatan pendampingan untuk meningkatkan pengetahuan dan sikap ibu hamil melalui promosi kesehatan, bimbingan dan konseling satu kali seminggu selama satu bulan. Kegiatan pendampingan terdiri dari tiga tahap, tahap pertama kader melakukan promosi kesehatan dengan di dampingi tim peneliti, tahap kedua kader melakukan promosi kesehatan dengan pengamatan peneliti dan tahap ketiga kader melakukan promosi kesehatan secara mandiri. Adapun media yang digunakan untuk kelompok intervensi adalah leaflet dan modul yang berisi tentang materi Program Perencanaan Persalinan dan Pencegahan Komplikasi (P4K).

Penelitian ini dilaksanakan selama lima bulan mulai bulan Juli sampai dengan November 2019 di Kota Bengkulu. Populasi penelitian adalah seluruh ibu hamil di Kota Bengkulu, sedangkan sampel penelitian adalah ibu hamil yang dipilih secara purposif dengan kriteria inklusi ibu hamil mempunyai tempat tinggal tetap di kota Bengkulu, dapat berkomunikasi dengan baik serta dapat membaca dan menulis. Berdasarkan perhitungan besar sampel dengan rumus uji hipotesis beda rata-rata di peroleh sampel minimal 60 orang ibu hamil, terdiri dari 30 orang kelompok intervensi dan 30 orang kelompok kontrol. Kelompok intervensi terpilih di wilayah kerja Puskemas Sukamerindu Kecamatan Sungai Serut dengan pertimbangan daerah tersebut merupakan daerah dengan jumlah kematian ibu tertinggi di Kota Bengkulu, sedangkan kelompok kontrol terpilih di wilayah kerja Puskesmas Anggut Atas yang mempunyai karakteristik yang sama namun di kecamatan yang berbeda yaitu Kecamatan Ratu Samban. Variabel independen adalah pemberdayaan kader sedangkan variabel dependen adalah pengetahuan dan sikap ibu hamil. Data dikumpulkan dengan menggunakan instrumen berupa kuesioner terstruktur yang terdiri dari 20 butir pertanyaan pengetahuan dan 20 butir pertanyaan sikap serta pertanyaan tentang karakteristik ibu hamil. Analisis data terdiri dari analisis univariat dan bivariat. Analisis univariat bertujuan mendeskripsikan variabel-variabel penelitian, sedangkan analisis bivariat untuk mengukur pengaruh pemberdayaan kader terhadap pengetahuan dan sikap ibu hamil tentang $\mathrm{P} 4 \mathrm{~K}$ dengan menggunakan paired t-test dan independent t-test. Penelitian ini mendapatkan persetujuan etik dari Komisi Etik Penelitian Poltekkes Kemenkes Bengkulu nomor: DM.01.04/056/10/2019. 
HASIL

Tabel 1.Karakteristik Ibu Hamil di Kota Bengkulu

\begin{tabular}{|c|c|c|c|c|c|}
\hline \multirow{3}{*}{ Variabel } & \multicolumn{4}{|c|}{ Kelompok } & \multirow{3}{*}{ p-value } \\
\hline & \multicolumn{2}{|c|}{ Intervensi $(\mathrm{n}=30)$} & \multicolumn{2}{|c|}{ Kontrol $(\mathrm{n}=\mathbf{3 0})$} & \\
\hline & $\sum$ & $\%$ & $\sum$ & $\%$ & \\
\hline \multicolumn{6}{|l|}{ Umur ibu } \\
\hline$<20$ dan $>35$ tahun & 6 & 20 & 2 & 6,7 & 0,254 \\
\hline $20-35$ Tahun & 24 & 80 & 28 & 93,3 & \\
\hline \multicolumn{6}{|l|}{ Pekerjaan } \\
\hline Bekerja & 3 & 10 & 9 & 30 & 0,107 \\
\hline Tidak Kerja & 27 & 90 & 21 & 70 & \\
\hline \multicolumn{6}{|l|}{ Sosial ekonomi } \\
\hline Pra Sejahtera & 3 & 10 & 0 & 0 & \\
\hline Sejahtera I & 10 & 33,3 & 11 & 36,7 & \\
\hline Sejahtera II & 1 & 3,4 & 4 & 13,3 & 0,167 \\
\hline Sejahtera III & 4 & 13,3 & 7 & 23,3 & \\
\hline Sejahtera III Plus & 12 & 40 & 8 & 26,7 & \\
\hline \multicolumn{6}{|l|}{ Pendidikan ibu hamil } \\
\hline $\mathrm{SD}$ & 2 & 6,7 & 1 & 3,4 & \\
\hline SMP & 3 & 10 & 3 & 10 & 0,806 \\
\hline SMA & 18 & 60 & 16 & 53,3 & \\
\hline PT & 7 & 23,3 & 10 & 33,3 & \\
\hline \multicolumn{6}{|c|}{ Pendidikan orang tua (Ibu) } \\
\hline Tidak Pernah Sekolah & 2 & 6,7 & 2 & 6,7 & \\
\hline SD & 10 & 33,3 & 9 & 30 & \\
\hline SMP & 11 & 36,7 & 3 & 10 & 0,085 \\
\hline SMA & 5 & 16,7 & 12 & 40 & \\
\hline PT & 2 & 6,7 & 4 & 13,3 & \\
\hline \multicolumn{6}{|c|}{ Pendidikan orang tua (Bapak) } \\
\hline Tidak Pernah Sekolah & 2 & 6,7 & 2 & 6,7 & \\
\hline $\mathrm{SD}$ & 9 & 30 & 9 & 30 & \\
\hline SMP & 10 & 33,3 & 2 & 6,7 & 0,074 \\
\hline SMA & 6 & 20 & 14 & 46,7 & \\
\hline PT & 3 & 10 & 3 & 10 & \\
\hline
\end{tabular}

Tabel 1 menunjukkan bahwa umur ibu hamil sebagian besar diantara 20-35 tahun, pekerjaan ibu sebagian besar tidak bekerja atau sebagai Ibu Rumah Tangga (IRT) baik pada kelompok intervensi maupun kelompok kontrol. Berdasarkan status sosial ekonomi, ibu hamil sebagian besar pada tahap sejahtera I. Pendidikan ibu hamil paling banyak tamat SMA baik pada kelompok kontrol maupun kelompok intervensi. Berbeda dengan pendidikan orang tua lebih banyak tamat SD dan SMP baik pendidikan Ibu maupun pendidikan Bapak. Berdasarkan hasil uji homogenitas diperoleh p-value $>00,5$ hal ini menunjukkan bahwa antara kelompok intervensi dan kelompok kontrol homogen (tidak ada perbedaan proporsi) dari faktor umur ibu ( $p$ value $=0,254)$, pekerjaan $(p$-value $=0,107)$, sosial ekonomi $\quad(p$-value $=0,167), \quad$ pendidikan $(p$ value $=0,806)$, pendidikan orang tua (ibu) ( $p$ value $=0,085)$, pendidikan orang tua (bapak) $(p$ value $=0,074$ ).

Tabel 2.Kepemilikan Buku KIA dan Stiker P4K

\begin{tabular}{|c|c|c|c|c|c|}
\hline \multirow{3}{*}{ Variabel } & \multicolumn{4}{|c|}{ Kelompok } & \multirow{3}{*}{ p-value } \\
\hline & \multicolumn{2}{|c|}{ Intervesi (n=30) } & \multicolumn{2}{|c|}{ Kontrol $(n=30)$} & \\
\hline & $\sum$ & $\%$ & $\sum$ & $\%$ & \\
\hline \multicolumn{6}{|l|}{ Buku KIA } \\
\hline Tidak ada & 5 & 16,7 & 11 & 36,7 & 0,144 \\
\hline Ada & 25 & 83,3 & 19 & 63,3 & \\
\hline \multicolumn{6}{|l|}{ Stiker P4K } \\
\hline Tidak ada & 10 & 33,3 & 19 & 63,4 & 0,01 \\
\hline Ada, tidak terisi lengkap & 13 & 43,3 & 4 & 13,3 & \\
\hline Ada, terisi lengkap tapi tidak ditempel & 3 & 10 & 0 & 0 & \\
\hline Ada, terisi lengkap dan ditempel & 4 & 13,4 & 7 & 23,3 & \\
\hline
\end{tabular}


Tabel 2 menunjukkan bahwa sebagian besar ibu hamil memiliki buku KIA. Hampir seluruh ibu hamil tidak ditemukan stiker P4K, walaupun ada stiker namun tidak terisi lengkap dan tidak ditempel. Berdasarkan hasil uji homogenitas diperoleh nilai $p$-value $>0,05$, hal ini menunjukkan bahwa antara kelompok intervensi dan kelompok kontrol dalam keadaan homogen (tidak ada perbedaan proporsi) dari faktor kepemilikan buku KIA ( -value $=0,144)$, kecuali pada faktor kepemilikan stiker $\mathrm{P} 4 \mathrm{~K} \quad(p$ value $=0,01)$.

Tabel 3. Pengaruh Pemberdayaan Kader terhadap Pengetahuan dan Sikap Ibu Hamil dalam Program Perencanan Persalinan dan Pencegahan Komplikasi (P4K)

\begin{tabular}{llrrr}
\hline Pengetahuan & \multicolumn{1}{c}{ Skor } & Sebelum & \multicolumn{1}{c}{ Sesudah } & p-value* \\
\multirow{2}{*}{ Intervensi } & Minimum-Maksimum & $45-90$ & $55-100$ & 0,0001 \\
& Rata-rata \pm SD & $70,67 \pm 14,07$ & $92,50 \pm 9,17$ & \\
\hline \multirow{2}{*}{ Kontrol } & Minimum-Maksimum & $25-95$ & $45-90$ & 0,351 \\
& Rata-rata \pm SD & $74,67 \pm 13,39$ & $71,00 \pm 15,40$ & \\
\hline p-value** & \multicolumn{1}{c}{ Skor } & Sebelum & Sesudah & p-value \\
\hline Sikap & Minimum-Maksimum & $62-91$ & $72-100$ & 0,0001 \\
\hline \multirow{2}{*}{ Intervensi } & Rata-rata \pm SD & $78,67 \pm 6,15$ & $86,12 \pm 8,56$ & \\
\hline \multirow{2}{*}{ Kontrol } & Minimum-Maksimum & $45-92$ & $46-92$ & 0,524 \\
& Rata-rata \pm SD & $77,46 \pm 10,47$ & $77,67 \pm 10,51$ & \\
\hline$p$ value & & 0,588 & 0,001 & \\
\hline
\end{tabular}

Tabel 3 menunjukkan bahwa pada awal sebelum dilakukan pemberdayaan kader rata-rata skor pengetahuan antara kelompok intervensi dan kelompok kontrol dalam keadaan homogen $(p$ value $=0,264>0,05)$. Setelah dilakukan intervensi menunjukkan ada perbedaan rata-rata skor pengetahuan antara kelompok intervensi dan kelompok kontrol ( $p$-value $=0,0001)$. Pengaruh pemberdayaan kader terhadap pengetahuan ibu hamil terlihat bahwa terjadi peningkatan rata-rata skor pengetahuan ibu hamil tentang P4K. Sebelum pemberdayaan kader rata-rata skor pengetahuan ibu hamil 70,67 setelah dilakukan intervensi meningkat menjadi 92,50. Hasil uji statistik menunjukkan bahwa ada perbedaan skor pengetahuan ibu hamil sebelum dan sesudah pemberdayaan kader $(p$-value $=0,0001)$. Berbeda dengan kelompok kontrol, hasil analisis menunjukkan bahwa tidak ada perbedaan ratarata skor pengetahuan ibu hamil sebelum dan sesudah intervensi $(p$-value $=0,351)$. Sebelum intervensi rata-rata skor pengetahuan ibu hamil 74,67 dan setelah intervensi menjadi 71,00.

Tabel 3 juga menunjukkan bahwa pada awal sebelum dilakukan pemberdayaan kader rata-rata skor sikap antara kelompok intervensi dan kelompok kontrol dalam keadaan homogen $(p$-value $=0,588>0,05) . \quad$ Setelah dilakukan intervensi hasil analisis lanjut menunjukkan bahwa terdapat perbedaan rata-rata skor sikap antara kelompok intervensi dan kelompok kontrol $(p$-value $=0,001)$. Pengaruh pemberdayaan kader terhadap sikap ibu hamil menunjukkan bahwa pada kelompok intervensi terdapat peningkatan rata-rata skor sikap ibu hamil, sebelum dilakukan pemberdayaan kader rata-rata skor pengetahuan ibu hamil 77,67 dan sesudah pemberdayaan meningkat menjadi 86,12. Hasil uji statistik juga menunjukkan bahwa ada perbedaan skor sikap ibu hamil sebelum dan sesudah pemberdayaan kader dengan nilai $p$-value $=0,0001$. Berbeda dengan kelompok kontrol sebelum dilakukan intervensi rata-rata skor sikap 77,46 setelah intervensi menjadi 77,67, hasil analisis lanjut juga menunjukkan tidak terdapat perbedaan ratarata skor sikap ibu hamil sebelum dan sesudah intervensi dengan nilai $p$-value $=0,524$.

\section{PEMBAHASAN}

\section{Karakteristik Ibu Hamil}

Penelitian ini menemukan bahwa sebagian besar umur ibu hamil terletak diantara 20-35 tahun. Umur tersebut merupakan umur yang aman untuk hamil dengan risiko kesehatan paling rendah.Namun penelitian ini juga menemukan masih terdapat ibu hamil berumur $<20$ dan $>35$ tahun. Kehamilan dibawah umur 20 tahun akan mengakibatkan rasa takut terhadap kehamilan dan persalinan dikarenakan pada umur tersebut ibu mungkin belum siap untuk memiliki anak dan organ reproduksi belum siap untuk hamil, demikian juga dengan umur lebih dari 35 tahun akan menimbulkan kecemasan terhadap kehamilan dan persalinan serta organ reproduksi ibu terlalu tua untuk hamil (Prawirohardjo, 2012). 
Jenis pekerjaan yang dimiliki ibu sebagian besar tidak bekerja atau sebagai Ibu Rumah Tangga (IRT). Pekerjaan sebagai IRT memungkinkan ibu hamil lebih banyak memiliki waktu untuk keluarga dan memiliki waktu untuk melakukan pemeriksaan kehamilan di fasilitas kesehatan.

Sosial ekonomi yang diukur melalui indikator keluarga sehat menunjukkan bahwa hampir sebagian besar ibu hamil berada pada tahap keluarga sejahtera I. Keluarga sejahtera I dalam indikator keluarga sehat adalah keluarga yang baru dapat memenuhi 6 indikator. Artiya keluarga belum bisa memenuhi kebutuhan anggota keluarga antara lainuntuk makan daging/ikan/telur yang merupakan sumber protein tinggi bagi ibu hamil.

Pendidikan terakhir yang pernah ditempuh Ibu hamil sebagian besar berpendidikan SMA. Pendidikan mempunyai peranan penting di dalam kehidupan berkeluarga karena mereka yang berpendidikan tinggi mempunyai pengetahuan yang lebih luas dibandingkan dengan yang berpendidikan rendah.Hal ini sejalan dengan penelitian Sutisna, dkk (2012) yang menemukan bahwa tingkat pendidikan berhubungan dengan kemampuan mengidentifikasi masalah kesehatan. Menurut laporan SDKI tahun 2017, Pendidikan ibu berperan terhadap tingkat kematian anak dan perinatal.Angka kematian balita paling tinggi terjadi diantara balita dari ibu yang tidak sekolah (82 per 1.000 kelahiran hidup), demikian juga tingkat kematian perinatal tertinggi (66 kematian per 1.000 kehamilan) adalah pada wanita yang tidak berpendidikan (BKKBN, BPS, Kemenkes, USAID, 2018). Lain halnya dengan kecenderungan dalam melakukan pemeriksaan antenatal care ke dokter kandungan lebih banyak pada wanita dengan tingkat pendidikan perguruan tinggi $(70 \%)$ dibandingkan dengan wanita yang tidak berpendidikan.

Berdasarkan hasil penelitian sebagian besar ibu hamil memiliki buku KIA, namun masih ada ibu hamil yang tidak memiliki buku KIA dengan alasan antara lain tidak tersedianya buku KIA saat memeriksakan kehamilan pada bidan setempat dan praktik dokter. Kepemilikan buku KIA bagi ibu hamil sangat penting agar bisa memantau perkembangan kehamilan selama 9 bulan.Didalam buku KIA juga terdapat materi terkait dengan kehamilan, persalinan, nifas dan bayi baru lahir. Dengan adanya buku KIA diharapkan ibu hamil dapat mengetahui apa saja yang harus dilakukan selama hamil, hal-hal yang perlu dihindari, tanda-tanda bahaya dalam kehamilan, persalinan dan nifas.
Selain buku KIA, stiker P4K sangat penting bagi keluarga yang memiliki ibu hamil. Stiker ini berisi informasi tentang ibu hamil meliputi nama ibu, tafsiran persalinan, penolong persalinan, tempat persalinan, pendamping persalinan, transportasi dan calon pendonor darah. Stiker harusnya terisi lengkap dan ditempel/dipasang di pintu atau jendela di depan rumah supaya masyarakat mengetahui bahwasanya ada ibu hamil di lingkungan mereka. Hasil penelitian membuktikan bahwa hampir sebagian besar ibu hamil tidak mendapatkan stiker $\mathrm{P} 4 \mathrm{~K}$, tidak terisi lengkap dan tidak ditempel di pintu atau jendela depan rumah. Menurut Departemen Kesehatan RI (2009), salah satu output $\mathrm{P} 4 \mathrm{~K}$ dengan stiker yang diharapkan adalah semua ibu hamil terdata dan rumahnya tertempel stiker P4K. Program P4K dengan stiker yang ditempel di rumah ibu hamil diharapkan memudahkan untuk mengidentifikasi setiap ibu hamil yang akan bersalin dan sudah mempunyai perencanaan persalinan dan kesiagaan jika menjalani persalinan dan menghadapi keadaan kondisi kegawatdaruratan (Badan Penelitian dan Pengembangan Kesehatan Kemenkes RI, 2016).

\section{Pengetahuan dan Sikap Ibu Hamil}

Pengetahuan adalah hasil tahu dan ini terjadi setelah orang melakukan pengindraan terhadap suatu objek tertentu. Pengetahuan dapat diperoleh antara lain melalui pendidikan baik kurikuler, nonkurikuler dan ekstrakurikuler, selain itu pengetahuan dapat diperoleh dari pengetahuan orang lain, seperti mendengar, melihat langsung dan melalui alat komunikasi seperti televisi, radio, buku dan lain-lain. Sedangkan sikap merupakan reaksi atau respons seseorang yang masih tertutup terhadap suatu stimulus atau objek. Manifestasi sikap itu tidak dapat langsung dilihat, tetapi hanya dapat ditafsirkan terlebih dahulu dari perilaku yang tertutup (Notoatmodjo, 2012).

Pada kondisi awal penelitian, pengetahuan ibu hamil masih rendah. Masih banyak ibu hamil yang belum tahu apa itu P4K, informasi penting apa saja yang ada dalam stiker P4K, berapa kali paling sedikit melakukan pemeriksaaan kehamilan, dan tanda bahaya dalam persalinan. Informasi tersebut merupakan informasi paling penting untuk diketahui oleh ibu hamil. Hal ini mengindikasikan bahwa pengetahuan ibu hamil perlu ditingkatkan.

Penelitian ini menemukan adanya perubahan skor pengetahuan ibu hamil tentang P4K sesudah dilakukan pemberdayaan kader. Artinya kader yang telah diberdayakan untuk 
mendampingi ibu hamil efektif meningkatkan pengetahuan ibu hamil tentang P4K.Hasil penelitian ini juga menemukan adanya perubahan skor sikap ibu hamil sesudah pemberdayaan kader. Peneliti melihat respon positif ibu hamil saat diberikan promosi kesehatan tentang P4K. Ibu hamil sangat antusias dan bergantian menanyakan hal-hal yang belum mereka pahami terkait materi yang sudah disampaikan. Setiap individu akan memiliki sikap yang positif yang mengarah pada penampilan perilaku tersebut, dan dapat terjadi sebaliknya (Subaris H, 2016).

\section{Pengaruh Pemberdayaan Kader terhadap Pengetahuan dan Sikap Ibu Hamil tentang P4K}

Pemberdayaan masyarakat adalah proses untuk meningkatkan pengetahuan, kesadaran, dan kemampuan individu, keluarga serta masyarakat untuk berperan aktif dalam upaya kesehatan yang dilaksanakan dengan cara fasilitasi proses pemecahan masalah melalui pendekatan edukatif dan partisipatif serta memperhatikan kebutuhan potensi dan sosial budaya setempat (Kemenkes RI, 2019). Sedangkan menurut Subaris H (2016), pemberdayaan adalah proses pemberian informasi secara terus menerus dan berkesinambungan mengikuti perkembangan sasaran, serta proses membantu sasaran, agar sasaran tersebut berubah dari tidak tahu menjadi tahu, dari tahu menjadi mau dan dari mau menjadi mampu melaksanakan perilaku yang diperkenalkan. Pemberdayaan masyarakat dilakukan dengan pendekatan pengembangan masyarakat, yakni bagaimana masyarakat mengembangkan kemampuannya serta bagaimana meningkatkan peran serta masyarakat dalam pengambilan keputusan (Subaris, H 2016). Proses pemberdayaan masyarakat menurut Suyono dalam Notoatmodjo (2012), paling tidak ada syarat yaitu kesadaran, kejelasan serta pengetahuan tentang apa yang akan dilakukan, pemahaman yang baik tentang keinginan berbagai pihak tentang hal-hal apa, dimana dan siapa yang akan diberdayakan dan adanya kemauan dan keterampilan kelompok sasaran untuk menempuh proses pemberdayaan.

Pada penelitian ini kelompok masyarakat yang diberdayakan adalah kader. Kader adalah setiap orang yang dipilih oleh masyarakat dan dilatih untuk menggerakkan masyarakat berpartisipasi dalam pemberdayaan masyarakat bidang kesehatan (Kemenkes RI, 2019). Pemberdayaan kader dalam penelitian ini adalah upaya meningkatkan kemampuan kader untuk mendampingi ibu hamil dalam program perencanaan persalinan dan pencegahan komplikasi (P4K) dengan cara memberikan promosi kesehatan secara berkelanjutan kepada ibu hamil baik dengan pendampingan peneliti, pengamatan peneliti maupun secara mandiri.

Pada awal penelitian yakni sebelum dilakukan pemberdayaan kader antara kelompok intervensi dan kelompok kontrol dalam keadaan homogen, artinya sebelum intervensi pengetahuan dan sikap ibu hamil antara kelompok intervensi dan kelompok kontrol dalam keadaan sama. Penelitian ini menemukan ada pengaruh pemberdayaan kader terhadap pengetahuan dan sikap ibu hamil yang dibuktikan dengan peningkatan pengetahuan dan sikap ibu hamil tentang $\mathrm{P} 4 \mathrm{~K}$. Terdapat perbedaan pengetahuan $(p$-value $<0,05)$ dan sikap $(p$ value $<0,05)$ ibu hamil sebelum dan sesudah pemberdayaan kader. Hasil analisis lanjut menunjukkan bahwa terdapat perbedaan rata-rata skor pengetahuan dan sikap antara kelompok intervensi dan kelompok kontrol $(p<0,05)$. Artinya pemberdayaan kader efektif dalam meningkatkan pengetahuan dan sikap ibu hamil. Pada akhirnya nanti diharapkan ibu hamil yang didampingi oleh kader mampu secara mandiri memelihara kesehatan mereka dan keluarga. Hal ini sejalan juga dengan penelitian Sakinah dan Ika (2015) yang menemukan bahwa pemberdayaan kader ANC dapat meningkatkan pengetahuan, sikap dan kunjungan ANC Ibu Hamil di Desa Kedungtulup Kecamatan Sumber Kabupaten Rembang.

Penelitian Agus dan Rachmawaty (2012) menunjukkan bahwa peran kader dalam upaya promotif di posyandu persentasenya meningkat dalam penyuluhan kepada TOGA, TOMA, dukun; pendataan ibu hamil, membantu bidan dalam melakukan PWS KIA, penimbangan ibu hamil, memasang stiker P4K, memberikan buku KIA kepada ibu hamil, kegiatan pencatatan dan pelaporan KIA, merujuk ibu hamil yang mengalami komplikasi kehamilan dan lain sebagainya.

Menurut Kamidah dan Yuliaswati (2018), kegiatan pendataan ibu hamil dapat berjalan dengan baik dengan melibatkan kader diseluruh desa/kelurahan, dengan demikian perlu adanya kerjasama yang baik antara bidan dan masyarakat. Demikian juga dengan penempelan stiker P4K dapat dilakukan bidan desa dibantu oleh kader. Selanjutnya berdasarkan penelitian Made, dkk (2017) menemukan bahwa terdapat hubungan antara penerapan Program Perencanaan Persalinan dan Pencegahan Komplikasi (P4K) oleh ibu hamil dengan kejadian komplikasi kehamilan di Puskesmas Doloduo Kabupaten Bolaang Mongondow. 
Demikian juga dengan penelitian Dewi, dkk (2019) menyebutkan ada hubungan yang signifikan antara peran kader posyandu dengan penerapan stiker $\mathrm{P} 4 \mathrm{~K}$ di wilayah Mojosongo Jebres Surakarta. Penelitian ini menemukan sebagian besar ibu hamil memiliki buku KIA. Buku tersebut penting dimiliki ibu hamil agar dapat memantau perkembangan kehamilan dari waktu ke waktu, disamping itu buku KIA juga di lengkapi dengan informasi penting antara lain tentang kehamilan, persalinan, masa nifas dan bayi baru lahir. Sehingga dapat disimpulkan bahwa peningkatan pengetahuan dan sikap ibu hamil tidak semata-mata karena pemberdayaan kader namun didukung dengan adanya kepemilikan buku KIA pada ibu hamil. Namun demikian, ibu hamil yang memiliki buku KIA tapi tidak memiliki keinginan untuk membaca dan menerapkannya selama kehamilan akan siasia saja, itulah sebabnya pemberdayaan kader sangat diperlukan untuk mendorong kesadaran, pengetahuan dan sikap ibu hamil ke arah yang lebih baik. Hal ini sejalan dengan penelitian Rizki, dkk (2017) menemukan bahwa kader yang

\section{DAFTAR PUSTAKA}

Agus, M., \& Rachmawaty, T. (2012). Peran Kader Kesehatan Dalam Program Perencanaan Persalinan dan Pencegahan Komplikasi Pada Ibu Hamil di Posyandu di Kota Mojokerto Provinsi Jawa Timur. Buletin Penelitian Sistem Kesehatan, 15 (4), 360-368.

Amalia, N.M., Purnomo, I., \& Nurlatif, V. (2016). Faktor-Faktor Yang Berhubungan Dengan Kematian Maternal di Kabupaten Batang. Jurnal Pena Medika, 6 (1), 1-18.

Badan Penelitian dan Pengembangan Kesehatan Kemenkes RI. (2016). Laporan Survei Indikator Kesehatan Nasional (Sirkesnas) 2016. Jakarta: Kemenkes RI.

BKKBN, BPS, Kemenkes, USAID.(2018). Survei Demografi dan Kesehatan Indonesia Tahun 2017. Jakarta: BKKBN.

Departemen Kesehatan RI. (2009). Pedoman Program Perencanaan Persalinan dan Pencegahan Komplikasi (P4K) dengan Stiker. Jakarta: Depkes RI.

Dewi, A.L., Setyorini, C.,\& Devi, S.A. (2019). Analisis Peran Kader Posyandu dengan Penerapan Program Perencanaan Persalinan dan Pencegahan Komplikasi (P4K) di Kelurahan Mojosongo Jebres Surakarta. Jurnal Kebidanan Indonesia, 10 (2), 132-142. berperan baik mampu meningkatkan kemungkinan ibu untuk memanfaatkan buku KIA 1,7 kali lebih besar dibandingkan kader yang kurang berperan.

\section{SIMPULAN}

Pemberdayaan kader efektif meningkatkan pengetahuan dan sikap ibu hamil tentang Program Perencanaan Persalinan dan Pencegahan Komplikasi (P4K).

Kementerian Kesehatan diharapakan dapat menyusun kebijakan dan upaya program terobosan bekerjasama dengan masyarakat terutama kader dan tokoh masyarakat yang merupakan masyarakat terdekat dengan ibu hamil. Demikian juga Dinas Kesehatan dan UPTD Dinas Kesehatan, diharapkan lebih meningkatkan pelaksanaan program secara berkesinambungan serta lebih mengoptimalkan peran aktif masyarakat terutama kader dalam Program Perencanaan Persalinan dan Pencegahan Komplikasi (P4K).

Dinas Kesehatan Provinsi Bengkulu. (2018). Profil Kesehatan Provinsi Bengkulu Tahun 2017. Bengkulu: Dinas Kesehatan Propinsi Bengkulu.

Dinas Kesehatan Provinsi Bengkulu. (2019). Profil Kesehatan Provinsi Bengkulu Tahun 2018. Bengkulu: Dinas Kesehatan Propinsi Bengkulu.

Kamidah.,\& Yuliaswati, E. (2018). Program Perencanaan Persalinan dan pencegahan komplikasi (P4K) Sebagai Upaya Menurunkan Angka Kematian Ibu. Gaster, XVI (1), 24-35.

Kemenkes RI. (2015). Rencana Strategis Kementerian Kesehatan Tahun 20152019: Keputusan Menteri Kesehatan RI No. HK.02.02/MENKES/52/2015. Jakarta: Kemenkes RI.

Kemenkes RI. (2015). Promosi Kesehatan Komitmen Global Dari Ottawa-JakartaHelsinki Menuju Rakyat Sehat. Jakarta: Kemenkes RI.

Kemenkes RI. (2019). Peraturan Menteri Kesehatan RI No. 8 Tahun 2019 Tentang Pemberdayaan Masyarakat Bidang Kesehatan. Jakarta: Kemenkes RI.

Made, N.W., Mulyadi., \& Karundeng, M. (2017). Hubungan Penerapan Program Perencanaan Persalinan dan Pencegahan 
Komplikasi Kehamilan Oleh Ibu Hamil Dengan Komplikasi Kehamilan di Puskesmas Doloduo Kab. Bolaang Mongondow. E-Journal Keperawatan (EKP), 5(1), 1-5.

Mariani, P., Widarini, P.,\& Pangkahila.A. (2013). Hambatan Dalam Implementasi Program Perencanaan Persalinan dan Pencegahan Komplikasi (P4K). Public Health and Preventive Medicine Archive, 1 (2), 109-114.

Notoadmodjo, S. (2010). Promosi Kesehatan Teori dan Aplikasi. Edisi Revisi. Jakarta: Rineka Cipta.

Notoadmodjo, S.(2012). Kesehatan Masyarakat: Ilmu dan Seni. Jakarta: Rineka Cipta.

Prawirohardjo, S. (2012). Ilmu Kebidanan. Jakarta: PT. Bina Pustaka Sarwono Prawirohardjo.

Pusat Data dan Informasi Kemenkes RI. (2014). Infodatin: Situasi Kesehatan Ibu. Jakarta: Kemenkes RI.

Pusat Data dan Informasi Kemenkes RI. (2014). Infodatin:Kondisi Pencapaian Program
Kesehatan Anak Indonesia. Jakarta: Kemenkes RI.

Rizki, E.W., Suryantoro, P.,\& Rokhanawati, D. (2017).Optimalisasi Peran Kader Dalam Pemanfaatan Buku KIA di Puskesmas Tegalrejo Kota Yogyakarta. Jurnal Unimus, 6(2), 112-119. http://jurnal.unimus.ac.id/index.php/jur_bi d/

Sakinah, V.,\& Ika, A.F. (2015). Upaya Peningkatan Pengetahuan, Sikap dan Kunjungan Antenatal Care (ANC) Ibu Hamil Melalui Pemberdayaan Kader ANC. Unnes Journal of Public Health, $4(1), 54-60$.

Subaris H. (2016). Promosi Kesehatan, Pemberdayaan Masyarakat dan Modal Sosial. Yogyakarta: Nuha Medika.

Sutisna, E.S., Karsid, R., Murti, B., Tri, D.K., Hartanto, R. (2012). Model Pemberdayaan Masyarakat Dalam Kemampuan Mengidentifikasi Masalah Kesehatan: Studi Pada Program Desa Siaga. Jurnal Kedokteran Yarsi, 20 (3), 128-142. 